\title{
Prof. Marc Amsler à son 70e anniversaire
}

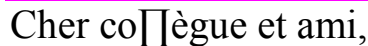

Vous fêtez ces jours votre 70c anniversaíre. Quelques-uns de vos élèues on† voulu vous témoigner leur affection en vous dédiant ce fascicule d'Ophthalmologica.

II aurait été facile de vous offrir un volume de travaux, car c'est avec joie que vos nombreux amis auraient apporté leur contribution. Cependant lors de votre $60 \mathrm{e}$ anniversaire déjà vous aviez exprimé le désir qu'on vous fasse grace d'un volume jubilaire. Nous n'avons pas voulu toutefois laisser passer cette occasion pour vous exprimer la reconnaissance de tous les oculistes suísses et etrangers, de vos anciens élèves pour tout ce que votre labeur et votre grande experience leur a donné.

Vous avez eu le bonheur de voir s'édifier I'æuvre de Gonin, vous Vavez continuée et perfectionnée. Vous avez élargi nos con-naissances des uvéites et avec vos élèves vous nous avez fait con-naître $\Gamma$ humeur aqueuse, « cette inconnue », íravaux couronnés par le magnifique rapport à la Société française d'Ophtalmologie. La kératophotographie a éclaíré bien des problèmes du kérato-cône et votre quadrille nous permet Vetude fonctionnelle des fines alterations maculaires. Vous avez été $\Gamma$ un des pionniers de $\Gamma$ ex-traction intracapsulaire de la cataracte. L'observation minutíeuse, methodique des malades, à laquelle vous avez toujours voué le meilleur de vous-même, nous a valu de nombreux travaux, le plus souvent enrichis de la belle iconographie dont vous avez le secret, et auxquels nous avons recours bien souvent pour nous éclairer. Grace à votre talent didactique, vous avez largement contribué à élever le niveau de Vophtalmologie suisse.

Bien qu'une loi inexorable vous oblige ci abandonner Ven-seignement aux étudiants, nous espérons tous que vous continuerez pendant longtemps encore à faire bénéficier les oculistes de vos connaissances el de votre experience. 


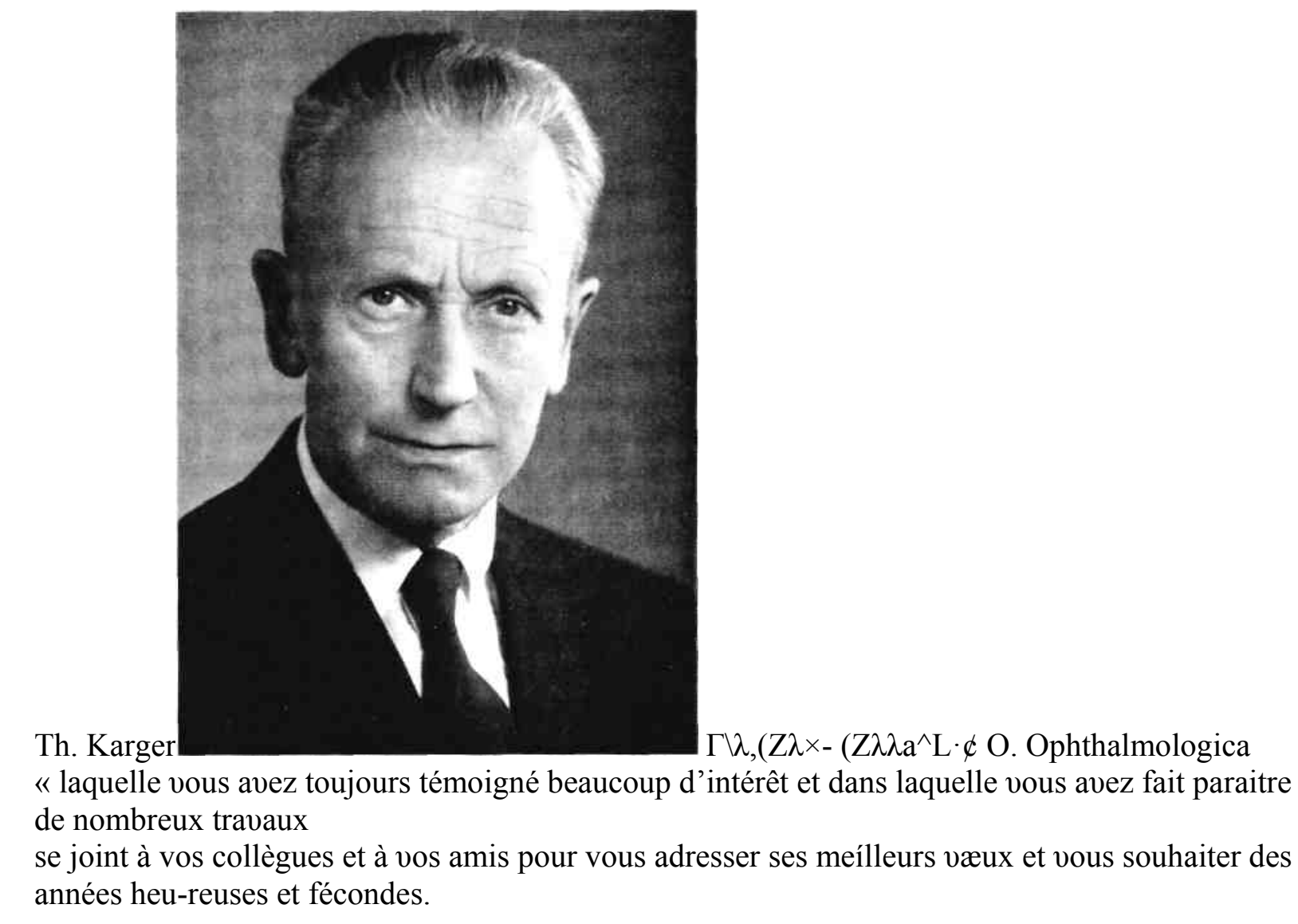

